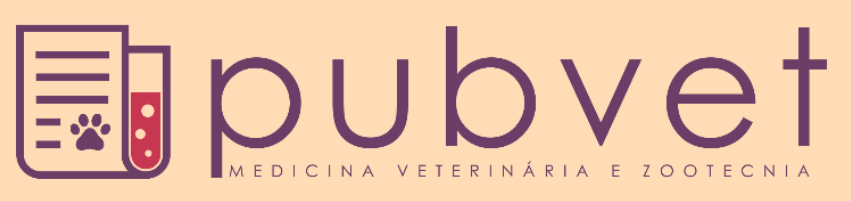

https://doi.org/10.31533/pubvet.v14n8a633.1-8

\title{
Osteomielite no membro pélvico de felino secundária à infecção bacteriana: Relato de caso
}

\author{
Maria Helena Dantas de Freitas $^{1 * \bullet}$, Márcio Nogueira Rodrigues ${ }^{2} \bullet$ \\ ${ }^{I}$ Discente do curso de Medicina Veterinária na Escola Superior Batista do Amazonas. Manaus- AM Brasil \\ ${ }^{2}$ Docente do curso de Medicina Veterinária na Escola Superior Batista do Amazonas. Manaus-AM Brasil \\ *Autor para correspondência: E-mail: helenadfreitas@yahoo.com.br
}

\begin{abstract}
Resumo. A osteomielite é definida como a inflamação óssea causada por agente infeccioso que pode ser bactéria ou fungo, abrangendo estruturas associadas como tecidos moles, periósteo e endósteo. As causas para o aparecimento da osteomielite são diversas como fraturas expostas, traumatismo e exposição óssea extensa. Os principais sinais clínicos encontrados são: claudicação no membro afetado, dor à palpação na região, edema e presença de descarga purulenta no local atingido. O diagnóstico envolve exames radiográficos, hematológicos e antibiograma. $\mathrm{O}$ tratamento é longo e exige persistência tanto do tutor como do profissional responsável. A melhor forma de prevenção é a atenção e cuidados em qualquer lesão que o animal apresente a fim de evitar focos de infecção. $O$ objetivo deste trabalho foi relatar um caso de um felino sem raça definida, com 3 anos de idade, com sintomatologia de dor, claudicação e presença de secreção mucopurulenta no membro pélvico, proveniente do município de Manaus, atendido no Centro Médico Veterinário de Manaus, abordando histórico clínico, diagnóstico e tratamento. Através do exame físico e dos exames radiográficos e antibiograma foi possível diagnosticar osteomielite. $\mathrm{O}$ tratamento consistiu em raspagem, remoção de fragmentos ósseos e o uso de diversos antibióticos sendo a lincomicina o fármaco de melhor ação para o tratamento. O animal apresentou recuperação satisfatória. Conclui-se que é necessário a abordagem correta mediante sinais clínicos e exames complementares como a cultura e antibiograma.
\end{abstract}

Palavras chave: inflamação, felino, lincomicina, osso

\section{Osteomyelitis in the feline pelvic limb secondary to bacterial infection: Case report}

Abstract. Osteomyelitis is defined as bone inflammation caused by an infectious agent that
may be bacteria or fungi, including associated structures such as soft tissues, periosteum
and endosteum. The causes for the appearance of osteomyelitis are diverse, such as exposed
fractures, traumatism and extensive bone exposure. The main clinical signs found are
claudication in the affected limb, pain on palpation of the region, edema and presence of
purulent discharge at the affected site. The diagnosis involves radiographic, hematological
and antibiogram examinations. The treatment is long and requires persistence of both the
tutor and the professional responsible. The best form of prevention is the attention and care
in any injury that the animal may present in order to avoid outbreaks of infection. The
objective of this study was to report a case of a 3-years-old feline, with symptomatology
of pain, claudication and presence of mucopurulent secretion in the pelvic limb, from the
city of Manaus, at the Veterinary Medical Center of Manaus, approaching clinical history,
diagnosis and treatment. Through physical and radiographic examinations and
antibiogram, it was possible to diagnose osteomyelitis. Treatment consisted of scraping,
removal bone fragments and use of various antibiotics, with lincomycin showing the best 
results. The animal presented a satisfactory recovery. It was concluded that, through clinical signs, the correct approach and complementary tests such as bacterial culture and antibiogram is necessary to treat the infection.

Keywords: inflammation, feline, lincomycin, bone

\title{
Osteomielitis en la extremidad pélvica felina secundaria a infección bacteriana: Reporte de un caso
}

\begin{abstract}
Resumen. La osteomielitis se define como la inflamación ósea causada por un agente infeccioso que puede ser bacterias u hongos, que abarca estructuras asociadas como tejidos blandos, periostio y endostio. Las causas para la aparición de la osteomielitis son diversas como fracturas expuestas, traumatismo y exposición ósea extensa. Los principales signos clínicos encontrados son: claudicación en el miembro afectado, dolor a la palpación en la región, edema y presencia de descarga purulenta en el local afectado. El diagnóstico consiste en exámenes radiográficos, hematológicos y antibiograma. El tratamiento es largo y requiere persistencia tanto del tutor como del profesional responsable. La mejor forma de prevención es la atención y cuidado en cualquier lesión que el animal presente para evitar brotes de infección. El objetivo de este trabajo fue relatar un caso de un felino mestizo, con 3 años, con sintomatología de dolor, claudicación y presencia de secreción mucopurulenta en el miembro pélvico, proveniente del municipio de Manaus, atendido en el Centro Médico Veterinario de Manaus, abordando el historial clínico, el diagnóstico y el tratamiento. A través del examen físico y de los exámenes radiográficos y antibiograma fue posible diagnosticar osteomielitis. El tratamiento consistió en raspado, remoción de fragmentos óseos y el uso de diversos antibióticos siendo la lincomicina el fármaco de mejor acción para el tratamiento. El animal presentó una recuperación satisfactoria. Se concluye que es necesario el abordaje correcto mediante signos clínicos y exámenes complementarios como la cultura y el antibiograma.
\end{abstract}

Palabras clave: inflamación, felino, lincomicina, hueso

\section{Introdução}

Osteomielite é uma inflamação de grau agudo ou crônico das estruturas ósseas com envolvimento da cavidade medular (Thomson, 1990). Essa patologia geralmente está associada às lesões traumáticas, cirúrgicas ou por via hematógena (Radostits et al., 2010). A osteomielite é invariavelmente provocada por um microrganismo infeccioso, como bactéria ou fungo, e disseminada por fatores ambientais dos tecidos locais que superam os mecanismos de defesa natural do animal (Birchard \& Sherding, 2008). Essa enfermidade é comumente associada a infecções por Staphylcoccus, Streptococcus, Proteus, Pseudomonas spp., E. coli e anaeróbios (Nelson \& Couto, 2015). Quando associada a infecção bacteriana, geralmente apresenta claudicação e lesão óssea dolorosa e inchada localizada. A doença pode ou não ser acompanhada por sinais sistêmicos de infecção. Nos casos crônicos, pode ocorrer perda de peso, e se desenvolverem tratos sinusais com secreções (Dunn, 2001).

Histórico, sinais clínicos e achados radiográficos são essenciais para a obtenção do diagnóstico e na determinação da extensão da lesão. A cultura para anaeróbios é particularmente importante nas infecções crônicas e naquelas associadas às mordeduras (Doige, 1987; Piermattei \& Flo, 2009).

O foco no tratamento da osteomielite é fornecer um ambiente local adequado à formação de tecido de granulação, propiciar a formação de calo macio, e permitir a regeneração do tecido ósseo (Birchard \& Sherding, 2008). Em uma infecção prolongada, a terapia terá que ser alterada e pode ser necessária uma exploração cirúrgica para determinar e remover a fonte da infecção (Bojrab, 2005).

O presente trabalho teve como objetivo apresentar um relato de caso em felino com osteomielite bacteriana ressaltando a importância da abordagem clínica completa e dos exames complementares bem como a cultura e antibiograma que fecha o diagnóstico da enfermidade e permite a escolha do antibiótico correto para uso no tratamento. 


\section{Relato de caso}

Foi atendido em uma clínica veterinária de Manaus um felino sem raça definida de três anos de idade, com peso corporal de $3,5 \mathrm{~kg}$. A principal queixa do tutor era que esse animal apresentava claudicação do membro pélvico esquerdo. $\mathrm{O}$ animal do presente relato tinha acesso à rua, estava com vermífugos e vacinação atualizados e não era castrado. O livre acesso à rua o levava a ter contato com outros felinos ocorrendo marcação de território e brigas resultando no traumatismo por mordedura em seu membro pélvico. O tutor relatou também que devido o animal passar algum tempo na rua o ferimento só foi observado dias depois da ocorrência.

No exame físico geral o animal apresentava-se pouco estressado devido ao ferimento, porém sempre em alerta, mucosas normocoradas, normorexia, normodipsia, normoquezia normúria, hidratação normal, TPC 02 de segundos, frequência cardíaca de $125 \mathrm{bpm}$, frequência respiratória de $25 \mathrm{rpm}$ e temperatura retal de $38,4^{\circ} \mathrm{C}$. Foi observada ocorrência de secreção mucopurulenta do local do ferimento, dor e sensibilidade no membro afetado quando ao toque. Era nítido o estresse do paciente devido à dor e a liberação de secreção do ferimento o que levava o mesmo a lamber o local, aumentando a proliferação de bactérias e consequentemente piorando o quadro clínico.

Durante o exame físico específico, foi observado que o paciente apresentava dificuldade de locomoção do membro pélvico esquerdo com claudicação leve, dor à palpação no local afetado e nas regiões adjacentes, presença de secreção mucopurulenta. O membro afetado (Figura 1) apresentava-se com características de fratura devido à mobilidade e crepitação notadas à palpação e aspecto de amolecimento com ferimento característico de mordedura, caracterizando um abscesso.
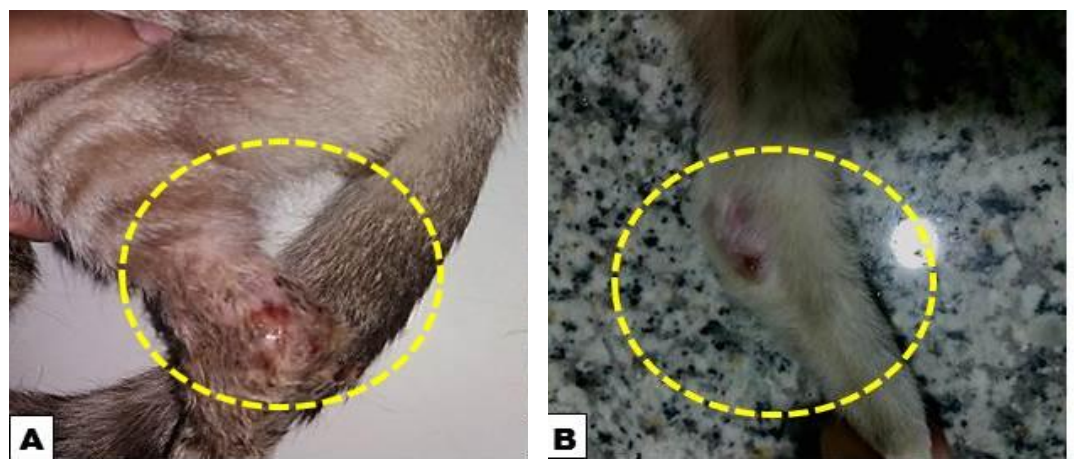

Figura 1. Evolução do quadro clínico do paciente. $\mathrm{m}(\mathbf{A})$ paciente no primeiro dia, observar que o membro apresentava secreção mucopurulenta. (B) Ferimento característico de mordedura.

Após realização da amamnese e exame físico foi solicitada radiografia do membro afetado devido as características de fratura e mobilidade observadas no exame físico. Na radiografia foi observado edema dos tecidos moles, proliferação periosteal e formação de sequestro ósseo (Figura 2). Foi realizada a aplicação de penicilina $(10 \mathrm{mg} / 5 \mathrm{~kg})$ e dexametasona $(0,125-0,5 \mathrm{mg} / \mathrm{kg})$ ambas realizadas pela via intramuscular.

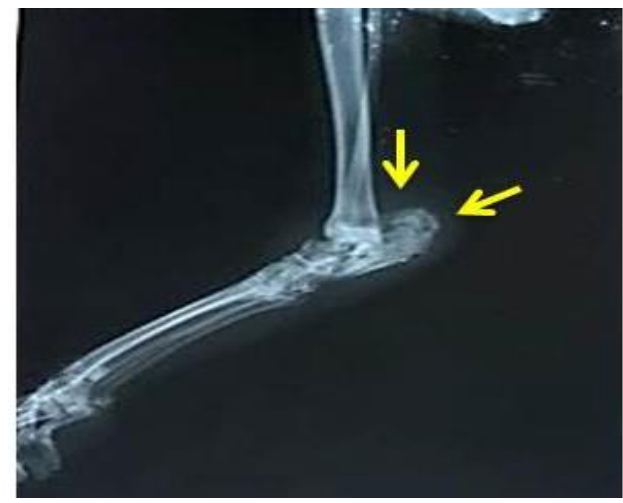

Figura 2. Radiografia do membro pélvico do paciente. Estão presentes edema dos tecidos moles, proliferação periosteal e formação de sequestro ósseo. 
Dias após essa aplicação o paciente retornou para reavaliação e não foi observada melhoria no quadro clínico do mesmo. Devido a isto, o veterinário levantou a hipótese de uma possível osteomielite devido a presença de secreção mucopurulenta constante e crepitação óssea no local do ferimento. Inicialmente esta hipótese não havia sido levantada e, portanto, foi tratada apenas como uma lesão traumática simples.

Foi solicitado hemograma completo e cultura com antibiograma da secreção do local afetado, a coleta foi realizada com swab estéril com meio de transporte Stuart. No hemograma não foram observadas nenhuma alteração digna de nota (Tabela 1).

Tabela 1. Perfil hematológico de felino sem raça definida com três anos de idade

\begin{tabular}{lcc}
\hline Hemograma & Resultado & Referência \\
\hline Eritrócito & $10,34 \mathrm{M} / \mu \mathrm{L}$ & $6.54-12.20$ \\
Hematócrito & $43,3 \%$ & $30.3-52.3$ \\
Hemoglobina & $14,9 \mathrm{~g} / \mathrm{dL}$ & $9.8-16.2$ \\
MCV & $41,9 \mathrm{fL}$ & $35.9-53.1$ \\
MCH & $14,4 \mathrm{pg}$ & $11.8-17.3$ \\
CHCM & $34,4 \mathrm{~g} / \mathrm{dL}$ & $28.1-35.8$ \\
RDW & $26,1 \%$ & $15.0-27.0$ \\
Plaquetas & $311 \mathrm{~K} / \mu \mathrm{L}$ & $151-600$ \\
Reticulócitos & $11,4 \mathrm{~K} / \mu \mathrm{L}$ & $3.0-50.0$ \\
\hline Leucograma & & $2.87-17.02$ \\
Leucócitos & $8,29 \mathrm{~K} / \mu \mathrm{L}$ & $2.30-10.29$ \\
Neutrófilos & $4,85 \mathrm{~K} / \mu \mathrm{L}$ & $0.01-0.26$ \\
Basófilos & $0,04 \mathrm{~K} / \mu \mathrm{L}$ & $0.17-1.57$ \\
Eosinófilos & $0,76 \mathrm{~K} / \mu \mathrm{L}$ & $0.92-6.88$ \\
Linfócitos & $2,25 \mathrm{~K} / \mu \mathrm{L}$ & $0.05-0.67$ \\
Monócitos & $0,39 \mathrm{~K} / \mu \mathrm{L}$ &
\end{tabular}

Fonte: Idexx Laboratories CMVM - Manaus - AM.

No exame de cultura e antibiograma, o resultado foi positivo para pesquisa de bactérias e negativo para pesquisa de fungos. Na pesquisa de bactérias o resultado foi positivo para Sthaphylococcus sp, pelo método Difusão em gelose pela técnica de Kirby Bauer (Tabela 2).

Tabela 2. Exame microbiológico sem raça definida com três anos de idade

\begin{tabular}{lcc}
\hline Cultura & Método & Resultado \\
\hline Positivo & Difusão em gelose pela técnica de Kirby Bauer & Sthaphylococcus sp. \\
\hline Antibiograma & Antibióticos Testados & Resultado \\
\hline 1 & Ácido Clav + Amoxacilina & Sensível \\
2 & Amicacina & Sensível \\
3 & Ampicilina & Resistente \\
4 & Cefalexina & Intermediário \\
5 & Ceftriaxona & Resistente \\
6 & Ciprofloxacino & Resistente \\
7 & Oxacilina & Sensível \\
8 & Penicilina & Sensível \\
9 & Enrofloxacino & Sensível \\
10 & Tetraciclina & Sensível \\
\hline 1 & Sulfa trimetropim & Resistente \\
\hline
\end{tabular}

Fonte: PRONTOVET - MANAUS - AM.

Mediante o resultado da cultura com antibiograma se procedeu a troca de protocolo terapêutico sendo utilizada a enrofloxacina $(2,5-5 \mathrm{mg} / 10 \mathrm{~kg}$ a cada 24 horas por 10 dias). Foi observado em consulta de retorno presença de fístulas no local afetado e nenhum progresso na melhora do quadro clínico. Houve 
uma suspensão no uso de antibióticos durante 10 dias. Foi necessário procedimento cirúrgico para retirada de fragmentos ósseos, raspagem e remoção da fonte de infecção (Figura 3).

No procedimento cirúrgico foi realizada tricotomia do local, assepsia com iodo e isolamento com pano de campo estéril. Foi feita a incisão no calcâneo com bisturi cabo $\mathrm{n}^{\circ} 10$ e lâmina $\mathrm{n}^{\circ} 22 \mathrm{com}$ a intenção de localizar o foco de infecção. Foi observada perda de estrutura óssea. Com a pinça Halstead Mosquito Curva foi realizada a raspagem e remoção de fragmentação óssea instável. O local foi lavado com clorexidina a $5 \%$ e foi feito curativo. O animal fez uso de colar elisabetano durante todo o período para evitar lambedura e novos focos de infecção.

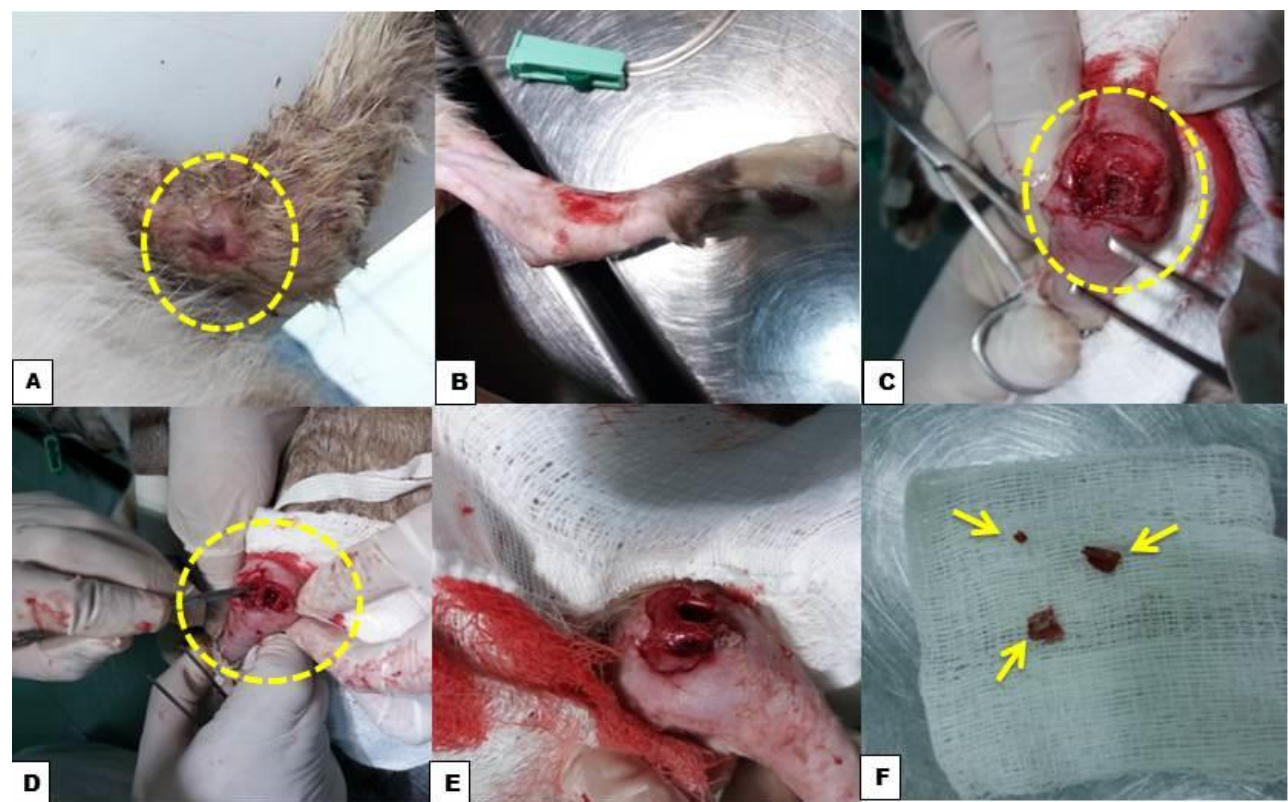

Figura 3. Exploração cirúrgica. Na figura (A) é possível observar que não houve progresso no tratamento realizado. (B) Tricotomia e assepsia. (C) Incisão e debridamento para retirada de fragmentos ósseos instáveis. (D) Raspagem e remoção do foco de bactéria. (E) Término do procedimento com visível perda de estrutura óssea (F) Fragmentos removidos.

No dia seguinte do procedimento cirúrgico foi iniciada uma nova antibioticoterapia. Foi prescrita para uso oral lincomicina ( $1 \mathrm{mg} / \mathrm{kg}$, a cada 12 horas por 20 dias). $O$ fármaco de eleição foi escolhido devido a lincomicina atuar bem em todos os tecidos, e para evitar resistência de fármacos utilizados anteriormente do resultado do antibiograma. Para aplicação no local, limpeza, assepsia e aplicação de pomada antimicrobiana a base de clorexidina diariamente. Após 15 dias de tratamento com a lincomicina foi observada uma melhora do quadro clínico (Figura 4A). Seguidos 15 dias ocorreu remissão da infecção e o local não apresentava mais presença de secreção, fístulas e a claudicação havia diminuído consideravelmente. Ao final dos 20 dias era nítida a resposta positiva ao último tratamento instituído a lesão havia cicatrizado perfeitamente por segunda intenção. Após 26 dias (Figura 4B) do procedimento cirúrgico e término do uso de antibióticos o resultado foi positivo, não sendo mais observada lesão no local e sim um processo de cicatrização satisfatório.
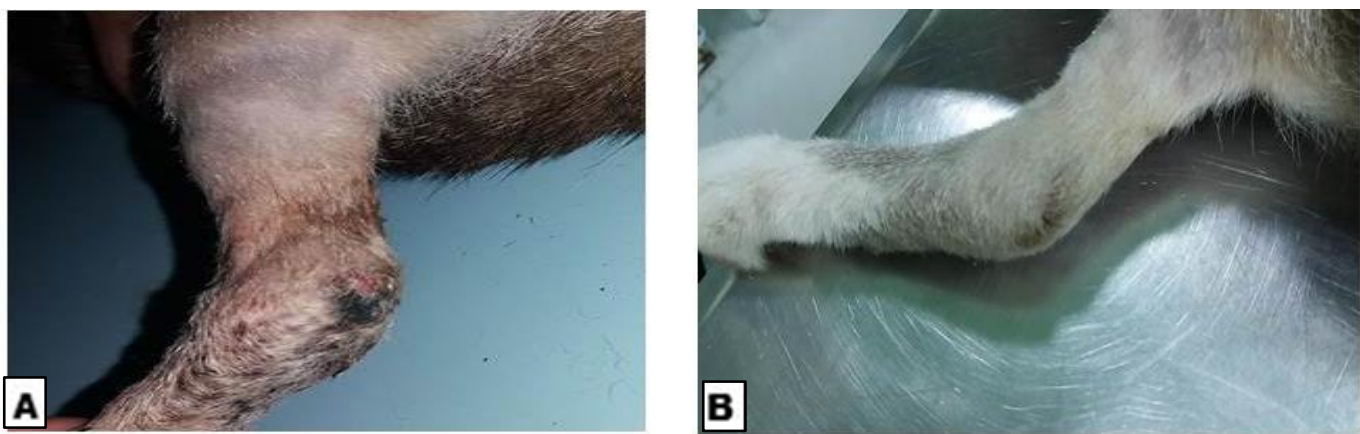

Figura 4. (A) Melhora do quadro clínico após 15 dias do procedimento cirúrgico, (B) Dia 26 após do último protocolo utilizado, paciente com perfeita cicatrização. 


\section{Resultados}

O paciente do presente relato tinha acesso constante a rua, o que o deixava mais exposto a situações adversas como brigas, disputa de fêmeas ou território, conforme citado por Lucas et al. (1998) e semelhante ao observado no animal avaliado. O animal deste relato apresentou sintomatologia clínica com ferimento no membro pélvico esquerdo, constante secreção mucopurulenta, leve claudicação, dor à palpação e característica de fratura com crepitação óssea. Provavelmente, deve ter ocorrido o rompimento do periósteo, o que leva o pus a se disseminar para os tecidos moles. Isquerto et al. (2000) afirmam que, eventualmente, este evento pode ocorrer confirmando o observado no paciente. Na primeira consulta, após anamnese e exame físico geral, foi realizada radiografia onde foram visualizados edema dos tecidos moles, proliferação periosteal e formação de sequestro ósseo. Chihara \& Segreti (2010) descrevem que estas alterações podem ser oriundas de um ferimento local ou hematógena, que se caracterizaria por reação purulenta, com amolecimento e necrose da parte óssea suprajacente, corroborando com o observado no nosso estudo.

A critério do Médico Veterinário que o atendeu e como protocolo da clínica foram administradas Penicilina e Dexametasona, na presente ocasião ainda não havia sido realizada a coleta de material para cultura e antibiograma somente radiografia, onde foi eliminada a suspeita de fratura. Cabe ressaltar que, $50 \%$ das bactérias dos gêneros Staphylococcus e Streptococcus mostram resistência à penicilina conforme relatos de Simionato et al. (2003).

Foi levantada a hipótese de diagnóstico de osteomielite devido à característica clínica da lesão onde o animal apresentava aumento de volume do membro afetado, claudicação e dor no local da lesão condizente com os sinais clínicos descritos por Doige (1987). A osteomielite secundária ocorre por solução de continuidade de um foco infeccioso (Isquerto et al., 2000) sendo o trauma devido à mordedura o foco da infecção, corroborando com o observado no paciente avaliado no presente relato e reafirmado por Fossum (2014) quando o autor cita que, os fatores que podem facilitar a entrada de microrganismos são: feridas por mordeduras de animais, penetração de corpo estranho, lesões por projeteis de arma de fogo, por extensão de tecidos moles adjacentes infectados ou necrosados e por fraturas abertas.

Em consulta de retorno observou-se que o tratamento não apresentava resultados satisfatórios e o paciente continuava com o mesmo quadro clínico, sem evolução. Pyles et al. (2005) relatam que, ao persistir a infecção, as partes moles podem ser atingidas e pode haver formação de fístula, que foi observada no retorno do paciente.

Foi solicitado hemograma completo e realizada a coleta de secreção do local afetado para exame de cultura e antibiograma. $\mathrm{O}$ hemograma completo não apresentou alterações hematológicas dignas de nota. Slatter (2007) descreve que esse exame é mais utilizado para que se tenha ideia de como estão as taxas das células sanguíneas e na procura de identificar a presença de algum agente infeccioso. O exame de cultura e antibiograma apresentou resultado positivo para Staphylococcus sp. A cultura bacteriana e fúngica são necessárias para determinação do agente etiológico e de sua sensibilidade às drogas antibacterianas (Lima et al., 2013). Com o resultado do antibiograma foi iniciado o tratamento com enrofloxacina. De acordo com Simionato et al. (2003) a enrofloxacina obteve bom desempenho sobre o gênero Staphylococcus. Com o término deste protocolo terapêutico não foram observadas melhoria no quadro clínico do paciente e a sintomatologia persistia contrariamente ao citado pelo autor citado anteriormente. Vale salientar que, embora tenha sido utilizado antibiótico com base em resultado da cultura e antibiograma, não se obteve sucesso terapêutico. Alguns estudiosos relatam sobre alterações retinianas e articulares em gatos que fazem uso de enrofloxacina. Contudo, segundo Cavalcante et al. (2009) o uso de enrofloxacino em gatos pode ser utilizada com mínimo risco de causar degeneração retiniana se utilizar a dose exata para o peso do animal, evitar infusão rápida intravenosa e redução da dose em gatos geriátricos ou com declínio de função renal.

Foi observado que, mesmo durante o uso da enrofloxacina, ainda continuava a drenagem de secreção purulenta pelas fístulas, segundo Denny \& Butterworth (2000) os trajetos fistulosos presentes nas infecções da doença, devem ser retirados, pois já se sabe que os mesmos servem como abrigos para as bactérias. Diante disto, foi realizado o procedimento de raspagem e retirada de fragmentos ósseos instáveis onde se encontrava o foco de bactéria. McGavin \& Zachay (2013) relatam que esses 
fragmentos isolados de osso (sequestros) e exsudatos associados podem ficar circundados por um denso colar de osso reativo (o invólucro). O uso de lincomicina foi iniciado no dia seguinte ao procedimento, segundo Maddison et al. (2011) a lincomicina penetra bem em todos os tecidos, incluindo o osso com isso têm sido usadas popularmente para tratar a osteomielite.

O tratamento de osteomielite é demorado, oneroso e consiste na insistência e dedicação do tutor em consorciação com o empenho do Médico Veterinário em obter a melhora do seu paciente. De acordo com Maddison et al. (2011) os atributos importantes do tratamento da osteomielite incluem uso de fármacos, tratamento prolongado, especialmente nas infecções crônicas e remoção cirúrgica do osso necrótico.

O paciente do presente relato estava aparentemente saudável o que resultou na demora do tutor em observar os sinais do mesmo, com isso o processo infeccioso teve aumento significativo. No início do tratamento a lesão era mínima o que levou a suposição de um ferimento comum, mas sem nenhum sucesso nos protocolos terapêuticos instituídos, os sintomas e sinais continuavam persistentes. Isto, levou o Médico Veterinário à realização de exames complementares para confirmação do diagnóstico. Mesmo com o uso do fármaco indicado pela sensibilidade os sinais clínicos de osteomielite eram evidentes, levando a exploração cirúrgica e remoção do foco de infecção. Após três trocas de antibioticoteria a lincomicina apresentou resultado satisfatório. Isto demonstra que, nem todos os pacientes respondem da mesma forma e que as variações individuais devem ser levadas em consideração, bem como a persistência do tutor para os cuidados devidos com o paciente e dedicação por parte do profissional Médico Veterinário.

\section{Conclusão}

A osteomielite muitas vezes ocorre de maneira silenciosa e merece um alerta constante. Uma simples lesão pode se tornar foco infeccioso severo colocando em risco a vida do paciente. Sendo assim, a realização de exames complementares como radiografia e cultura com antibiograma constituem ferramentas essenciais para o diagnóstico da osteomielite e obtenção de sucesso no tratamento.

\section{Referências bibliográficas}

Birchard, S. J., \& Sherding, R. G. (2008). Manual Saunders: clínica de pequenos animais. In Ed. Roca (Vol. 3).

Bojrab, M. J. (2005). Técnicas atuais em cirurgia de pequenos animais. Editora Roca.

Cavalcante, L. F., Gôuvea, A. S., \& Marques, J. V. (2009). Degeneração retiniana em gatos associada ao uso de enrofloxacina. Acta Veterinaria Brasilica, 3(2), 62-68.

Chihara, S., \& Segreti, J. (2010). Osteomyelitis. DisMon, 1(56), 6-31.

Denny, H. R., \& Butterworth, S. J. (2000). A guide to canine and feline orthopaedic surgery. Blackwell Science.

Doige, C. E. (1987). Multiple cartilaginous exostoses in dogs. Veterinary Pathology, 24(3), 276-278. https://doi.org/10.1177/030098588702400314

Dunn, J. K. (2001). Tratado de medicina de pequenos animais. Roca.

Fossum, T. W. (2014). Cirurgia de pequenos animais (4th ed., Vol. 1). Elsevier Brasil.

Isquerto, R., Laganaro, S. L., Garbelini, M. E., Tanaka, N. M., Sturion, M. A. T., \& Sturion, D. J. (2000). Aspectos clínicos e tratamento da osteomielite. Journal of Health Sciences, 2(1), 151-160.

Lima, T. B., Leal, L. M., Morato, G. O., Marinho, P. V. T., Moraes, P. C., \& Minto, B. W. (2013). Osteomielite fúngica em fratura de tíbia de cão. Relato de caso. Revista Brasileira de Ciência Veterinária, 20(3), 132-136. https://doi.org/10.4322/rbcv.2014.069

Lucas, S. R. R., Hagiwara, M. K., Reche Júnior, A., \& Germano, P. M. L. (1998). Ocorrência de anticorpos antitoxoplasma em gatos infectados naturalmente pelo vírus da imunodeficiência dos felinos. Brazilian Journal of Veterinary Research and Animal Science, 35(1), 41-45. https://doi.org/10.1590/S1413-95961998000100008 
Maddison, J. E., Page, S. W., \& Church, D. B. (2011). Farmacologia clínica de pequenos animais. In G. A. Philip \& A. F. Thomas (Eds.), Medicamentos e reprodução (pp. 520-537). Elsevier Brasil.

McGavin, D., \& Zachay, J. F. (2013). Bases da patologia em veterinária. Elsevier Brasil.

Nelson, R. W., \& Couto, C. G. (2015). Medicina interna de pequenos animais (Issue 1). Elsevier Editora.

Piermattei, B. D. L., \& Flo, G. L. (2009). Ortopedia e tratamento das fraturas dos pequenos animais (3 ed.). Editora Manolo.

Pyles, M. D., Bento, M. A. F., Mendes, R. M., \& Alvin, N. C. (2005). Osteomielite por ferida penetrante em equino. Revista Científica Eletrônica de Medicina e Veterinária, 5, 1-5.

Radostits, O. M., Gay, C. C., Blood, D. C., Hinchcliff, K. W., \& McKenzie, R. A. (2010). Clínica Veterinária: um tratado de doenças dos bovinos, ovinos, suínos, caprinos e eqüinos (Vol. 1). Guanabara Koogan.

Simionato, A. C., Ramos, M. C. C., \& Coutinho, S. D. A. (2003). Isolamento de bactérias aeróbias e sua sensibilidade a antimicrobianos em processos de osteomielite canina. Arquivo Brasileiro de Medicina Veterinária e Zootecnia, 55(2), 148-154. https://doi.org/10.1590/s0102$\underline{09352003000200004}$

Slatter, D. H. (2007). Manual de cirurgia de pequenos animais. Manole.

Thomson, R. G. (1990). Patologia veterinária especial (Vol. 1). Manole.

Recebido: 28 de março, 2020.

Aprovado: 26 de abril, 2020.

Disponível online: 25 de agosto, 2020.

Licenciamento: Este artigo é publicado na modalidade Acesso Aberto sob a licença Creative Commons Atribuição 4.0 (CC-BY 4.0), a qual permite uso irrestrito, distribuição, reprodução em qualquer meio, desde que o autor e a fonte sejam devidamente creditados. 